\title{
Parental occupational exposure to benzene and the risk of childhood cancer: a census-based cohort study
}

Ben Daniel Spycher ${ }^{1}$, Judith Eva Lupatsch ${ }^{1,2}$, Anke Huss ${ }^{3}$, Johannes Rischewski ${ }^{4}$, Christina Schindera ${ }^{1,5}$, Adrian Spoerri ${ }^{1}$, Roel Vermeulen ${ }^{3}$, Claudia Elisabeth Kuehni ${ }^{1}$ for the Swiss Paediatric Oncology Group and the Swiss National Cohort Study Group

1) Institute of Social and Preventive Medicine (ISPM), University of Bern, Bern, Switzerland

2) INSERM U1153, Epidemiology and Biostatistics Sorbonne Paris Cité CRESS-EPICEA, University Paris-Descartes, Paris, France

3) Institute for Risk Assessment Sciences (IRAS), Utrecht University, Utrecht, The Netherlands

4) Department of Oncology/Haematology, Children's Hospital, Cantonal Hospital Lucerne, Lucerne, Switzerland

5) University Children's Hospital Basel (UKBB), Basel, Switzerland

\section{Correspondence:}

Ben Spycher, University of Bern, Institute of Social and Preventive Medicine (ISPM),

Finkenhubelweg 11, CH-3012 Bern, Switzerland

Tel. +41316313346

Fax +41316313520

Email: ben.spycher@ispm.unibe.ch

Conflict of interests: The authors declare they have no actual or potential conflict of interests. 


\begin{abstract}
Background: Previous studies on occupational exposures in parents and cancer risks in their children support a link between solvents and paints with childhood leukaemia. Few studies have focused specifically on benzene.
\end{abstract}

Objectives: To examine whether parental occupational exposure to benzene is associated with an increased cancer risk in a census-based cohort of children.

Methods: From a census-based cohort study in Switzerland, we included children aged $<16$ years at national censuses $(1990,2000)$. We retrieved parental occupations reported at census and assessed exposure to benzene using a job exposure matrix. We identified incident cancer cases through record linkage with the Swiss Childhood Cancer Registry. We fitted Cox proportional-hazards models to assess associations between exposures and the following outcomes: any cancer, leukaemia, acute lymphoid leukaemia (ALL), acute myeloid leukaemia (AML), lymphoma, non-Hodgkin lymphoma, CNS tumours, and glioma. We adjusted models for a range of socio-economic, perinatal and environmental factors.

Results: Analyses of maternal (paternal) exposure were based on 9.0 (13.2) million person years at risk and included 1004 (1520) diagnoses of cancer, of which 285 (438) had leukaemia, 186 (281) lymphoma, 227 (339) a CNS tumour. Maternal exposure was associated with an increased risk of childhood leukaemia (hazard ratio 1.73, 95\% CI 1.12-2.67) and ALL (1.88, 1.16-3.04). We found little evidence of an association for other outcomes or for paternal exposure. Adjusting for potential confounders did not materially affect the results.

Conclusions: This nationwide cohort study suggests an increased risk of leukaemia among children whose mothers were exposed to benzene at work. 


\section{Highlights:}

- A job exposure matrix was used to assess occupational benzene exposure in parents

- A higher risk of leukaemia was observed in offspring of exposed mothers

- In utero exposure is a plausible explanation for this finding

Key words: air pollution, aromatic hydrocarbons, job exposure matrix, leukaemia, lymphoma, occupational hygiene, paints, solvents, tumours of the central nervous system, workplace

\section{Abbreviations:}

ALL acute lymphoid leukaemia

AML acute myeloid leukaemia

BEN-JEM benzene job exposure matrix

CNS central nervous systemHR hazard ratio

ICCC-3 International Classification of Childhood Cancer $3^{\text {rd }}$ edition

ISCO International Classification of Occupations

JEM job exposure matrix

SCCR Swiss Childhood Cancer Registry

SEP socioeconomic position

SNC Swiss National Cohort study 


\section{Introduction}

Cancer is rare in childhood and the extent to which risks are determined by environmental risk factors is uncertain. It has been suggested that parents' occupational exposure to mutagenic substances, such as benzene, may increase the risk of cancer in their offspring (Colt and Blair 1998; Pyatt and Hays 2010). Proposed causal pathways include genetic alterations in parental germ cells, particularly of the father's sperm (Anderson et al. 2000), trans-placental exposure of the foetus during pregnancy (Anderson et al. 2000; Badham et al. 2010), or postnatal exposure of the child to substances brought home from the work place (Colt and Blair 1998). Benzene has been widely used as a solvent in paints and adhesives in the past. In occupationally exposed adults, it causes acute myeloid leukaemia (AML) and possibly other blood cancers including acute lymphoid leukaemia (ALL), chronic lymphoid leukaemia, multiple myeloma and non-Hodgkin lymphoma (Chiu and Hou 2015; IARC 2012; Vlaanderen et al. 2011; 2012). The major source of benzene exposure in children is ambient air pollution (Duarte-Davidson et al. 2001). Benzene concentrations tend to be higher indoors where children spend most of their time, particularly if a family member smokes (Duarte-Davidson et al. 2001; Wallace 1996). Maternal intake of benzene, for instance from occupational exposure, can be transmitted to children prenatally through transplacental migration or in infancy through breastfeeding. Cord blood has been found to contain benzene in similar quantities as maternal blood (Dowty et al. 1976) and benzene has been found in breastmilk (Fabietti et al. 2004).

Numerous studies have investigated associations between parental occupational exposures and childhood cancers including leukaemia, ALL, and CNS tumours. A review of studies up to 1997 supports increased risks associated with benzene-related occupational exposures such as exposure to paints, solvents or exhaust fumes both for childhood leukaemia and CNS tumours (Colt and Blair 1998). For childhood leukaemia, The majority of more recent studies have also reported increased risks associated with benzene-related occupational exposures, either for paternal (Feychting et al. 2001; Metayer et al. 2016; Miligi et al. 2013; Reid et al. 2011) or maternal exposure (Infante-Rivard et al. 2005; McKinney et al. 2008; Miligi et al. 2013; Reid et al. 2011; Schuz et al. 2000; Shu et al. 1999). However, two large recent studies (Bailey et al. 2014; Keegan et al. 2012), including a study of 
the Childhood Leukaemia International Consortium (CLIC) focusing on parental occupational exposure to paint (Bailey et al. 2014), found no evidence of an association. Most previous studies looked at broad occupational or substance groups while only a minority considered exposure to benzene specifically. Results from studies that have specifically investigated occupational exposure to benzene also tend to support a link with childhood leukaemia, particularly for maternal exposure (Carlos-Wallace et al. 2016). Since the review by Colt and Blair, increased risks in children of parents with benzene related occupational exposures have also been reported for CNS tumours (Ali et al. 2004; Cordier et al. 1997; Cordier et al. 2001; Keegan et al. 2013; McKean-Cowdin et al. 1998; Peters et al. 2014; Peters et al. 2013), lymphoma (Mutanen and Hemminki 2001), and non-Hodgkin lymphoma (McKinney et al. 2008; Miligi et al. 2013).

Various methodological issues make it difficult to draw firm conclusions from this research. Most previous studies were case-control studies susceptible to selection bias. For example, if controls with low socioeconomic status - and thus higher risk of exposure - are less likely to participate while cases are likely to participate regardless of socioeconomic status, the estimated association between exposure and outcome will be biased upward (Mezei et al. 2006). To our knowledge, only two previous studies were cohort studies (Feychting et al. 2001; Mutanen and Hemminki 2001) and none of these specifically investigated maternal occupational exposure to benzene. Studies relying on selfreported exposure to specific substances are susceptible to recall bias (Schuz et al. 2003). Furthermore, most previous studies investigated a wide range of broad occupational or exposure groups in an exploratory manner, without corrections for multiple testing.

We investigated the association between parents' occupational exposure to benzene and cancer in their offspring in a nation-wide census-based cohort study in Switzerland. The study is based entirely on near-complete routine data and is thus free of participation bias. We investigated multiple diagnostic categories including all cancers, leukaemia, acute lymphoblastic leukaemia (ALL), lymphoma, CNS tumours and glioma. To minimize multiple testing issues, we focused exclusively on exposure to benzene. We assessed exposure for occupations reported at census using a custom-made job exposure matrix (JEM). 


\section{Material and Methods}

\subsection{Population}

We included children from the Swiss National Cohort (SNC) study, a research platform that probabilistically links individual records from various national datasets including censuses and datasets on mortality, migration, and births (Bopp et al. 2009; Spoerri et al. 2010). The cohort consists of all individuals registered in national censuses in 1990 and 2000. Children enter the cohort on the date of the first census they are recorded in (1990 or 2000) and are followed-up to emigration, death or the end of 2008. Participation in the census was mandatory, resulting in a coverage of $98.6 \%$ in 2000 (Bundesamt für Statistik 2005). The census questionnaires addressed a wide range of demographic and socioeconomic information including occupation and the number and birth years of children. All household members had to report their position within the household.

We included children from the SNC if they were aged 0-15 years at census, if their mother or father could be identified, and if the identified parent(s) reported an occupation (Figure 1). We identified parents by linking adults reporting to have children with matching children living in the same household.

We identified primary cancers diagnosed in included children through probabilistic record linkage with the Swiss Childhood Cancer Registry (SCCR). We included all cases diagnosed in Switzerland during the study period 1990-2008 at age 0-14 years. Linkage variables included sex, date of birth, parental dates of birth, geo-coded residence at census, municipality of residence at census and at birth, and nationality. The SCCR is a population based registry that records diagnoses of cancers made in Switzerland in children and adolescents aged $\leq 20$ years. Completeness of case ascertainment was 91\% since 1985 and $\geq 95 \%$ since 1995 (Schindler et al. 2015). Ethics approval for this study was granted through the Ethics Committee of the Canton of Bern to the SCCR on the 22th of July 2014 (KEK-BE: 166/2014).

\subsection{Outcomes}


Cancer diagnoses were classified according to the third edition of the International Classification of Childhood Cancer (ICCC-3) (Michel et al. 2007; Michel et al. 2008; Steliarova-Foucher et al. 2005). We investigated the following outcomes: all cancers (all ICCC-3 diagnostic groups), leukaemia (ICCC-3 main group I), acute lymphoid leukaemia (ALL) (group Ia), acute myeloid leukaemia (AML) (group Ib), lymphoma (main group II), non-Hodgkin lymphoma (group IIb and IIc), CNS tumours (main group III; this also includes tumours of non-malignant or uncertain behaviour) and gliomas (groups IIIa, IIIb, or IIId) (Steliarova-Foucher et al. 2005).

\subsection{Assessing occupational exposure to benzene}

We used a novel job exposure matrix (BEN-JEM) based on the International Classification of Occupations 1988 (ISCO-88) to assess parental occupational exposure to benzene. We used the occupations reported by parents in the earliest census that the child was recorded in. Persons not belonging to the paid labour force (e.g. homemakers, students or pensioners) are grouped under a single category, which we refer to here as "not economically active".

BEN-JEM is based on expert assessment by one of the authors (RV) and estimates for each ISCO-88 job-code the proportion of workers exposed $(\mathrm{P})$ in a given job category and the mean level of exposure (L, expressed in parts per million) among the exposed by time period (1960-84, 1985-94, 1995-97, 1998-2000). The BEN-JEM was developed for application in general population studies, and given that specific occupational exposures are relatively rare, exposure assessment was designed to be more specific than sensitive.

For the purpose of these analyses, we assigned the product of the proportion of workers exposed and the level of exposure $(p \times L)$ to the ISCO-88 job-codes. Exposure at the 2000 census was based on averaged values (of $p \times L$ ) for the time periods 1995-97 and 1998-2000. The period 1985-94 was used for exposure at the 1990 census. Occupations held at childrens' first census may have already been held earlier when exposure levels were higher. For this reason, we also assessed exposures (for reported occupations) using the time period corresponding to 10 years before the census: values $(p \times L)$ from period 1985-94 for the 2000 census and from 1960-84 for the 1990 census.

\subsection{Potential confounders}


We used a directed acyclic graph to guide our selection of potential confounders to be considered in analyses (Supplemental Material Figure S1). We obtained data on educational level of the household reference person (compulsory, upper secondary, or tertiary education) and crowding (number of persons per household in tertiles) from census records. Data on birth order $\left(1^{\text {st }}, 2^{\text {nd }}, 3^{\text {rd }}\right.$ or later), and birth weight (tertiles) were available from birth records. Geocoded place of residence at census was available from the SNC and additionally allowed us to obtain the following data: the Swiss neighborhood index of socio-economic position (Swiss-SEP) (Panczak et al. 2012), distance to nearest highway $(<100,100-250,250-500, \geq 500 \mathrm{~m})$ (Spycher et al. 2015a), distance to nearest petroleum refinery $(<1,1-2, \geq 2 \mathrm{~km})$, distance to petrol station $(<100,100-250, \geq 250 \mathrm{~m})$, distance to motor vehicle service station $(<100,100-250, \geq 250 \mathrm{~m})$; dose rate of ionizing background radiation including terrestrial gamma and cosmic radiation $(<100,100-150,150-200, \geq 250 \mathrm{nSv} / \mathrm{h})($ Spycher et al. 2015b), distance to nearest power line of 220 or $380 \mathrm{kV}(<100,100-250, \geq 250 \mathrm{~m})$, and estimated strength of electromagnetic field from radio and TV transmitters $(<0.05,0.05-0.2, \geq 2 \mathrm{~V} / \mathrm{m})($ Hauri et al. 2014).

\subsection{Statistical analyses}

Our main analyses included only children whose parent(s) reported an ISCO-88 coded occupation. In sensitivity analyses, we additionally included children of not economically active parents assigning them the exposure level of zero. We ran separate analyses for paternal and maternal exposure.

We used Cox proportional hazards regression with age as the underlying time scale to compare the risk of childhood cancer across different exposure categories. Follow-up time began at entry into the cohort and ended at cancer diagnosis, emigration, death, the child's $16^{\text {th }}$ birthday, or the end of the study period (31 December 2008), whichever occurred first. The exposure variable showed a left skewed distribution. We categorized the exposure as 0 (unexposed), $>0-2,>2-10$, and from there on in steps of 10. Percentiles corresponding to these values are reported in Table $\mathbf{1 .}$

We adjusted for potential confounders in three steps. Initially, models were adjusted for sex, year of birth (5-year categories), and first census $(1990,2000)$ (minimally adjusted models). We adjusted for first census because exposure levels dropped considerably between these two census time points. Any factors potentially leading to different incidence rates among children entering a decade later, 
including, for example, secular trends in incidence or registration coverage, might thus confound the association of interest. Next, we added all other potential confounders except birth order and birth weight (partially adjusted models). In a final step, we added birth order and birth weight (fully adjusted models). The reason for this was that perinatal information was only available for children linked to a matching birth record. This linkage excluded children aged $>10$ years at census (due to poor linkage success) and children born abroad. There was thus a considerable proportion of missing values in birth order and birth weight in analyses of maternal (46\%) and paternal exposure (41\%).

In sensitivity analyses, we first additionally included children of not economically active parents. Exposure in this group is difficult to assess and is likely to originate from shared environments with the children (e.g. benzene concentrations in homes). We therefore did not include these children in the main analysis. However, one could argue that exposure levels are well below those of exposed occupational and that these children could be included as unexposed. Second, we included only children born in Switzerland because, for these children, parental occupations at census are more likely to correspond to occupations held before birth of the child and prenatal exposure may be more relevant than postnatal exposure. Furthermore, BEN-JEM may not be appropriate for occupations in the countries that immigrants come from. Third, we included only children linked to a birth record to assess whether any changes in effect estimates due to inclusion of birth order and birth weight as potential confounders were due to restriction to this sample rather than to confounding. Lastly, we restricted analyses to children aged 0-4 years at the first census, i.e. the time point of exposure assessment. For this subgroup, the likelihood that assessed exposure reflects the parent's occupational exposure during pregnancy and infancy is higher.

\section{Results}

\subsection{Characteristics of included population}

Of the $2,129,264$ children in the SNC who were aged $<16$ years at the time of entry into the cohort we were able to identify the mothers of 2,029,315 (95.3\%) and the fathers of 1,890,658 (88.8\%) children (Figure 1). More mothers than fathers reported not being economically active. After excluding children of these parents and parents with no reported or uncertain occupation and children diagnosed 
with cancer prior to entry into the cohort, we included $1,138,826$ (53.5\% of all children) and $1,664,801$ children (78.2\%) in the main analyses for maternal and paternal exposure respectively (Figure 1). We identified 1004 diagnoses of cancer (285 leukaemia, 227 CNS tumours) during 9.0 million person years of follow-up (median follow-up time 8.1 years) of children included for analyses of maternal exposure. The corresponding number for paternal exposure was 1479 cancer diagnoses (438 leukaemia, 339 CNS tumours) during 13.2 million person years of follow-up (median 8.1 years). We provide a more detailed description of the time to event data of included children stratified by age at entry and census in the Supplemental Material Table S1.

Compared to children excluded from main analyses, included children tended to come from households with less crowding and higher educational level, and to live in neighbourhoods of higher socio-economic position and not in city centres (Table 1). Occupational exposure to benzene was more common among fathers than among mothers (Table 1). The most common occupations among exposed mothers and fathers are listed in Tables $\mathbf{S 2}$ and $\mathbf{S 3}$ of the Supplemental Material.

\subsection{Maternal exposure to benzene and childhood cancer}

Children of exposed mothers had a greater risk of developing leukaemia, particularly ALL (Table 2). In minimally adjusted models, the hazard ratio (HR) comparing children of exposed to those of unexposed mothers was 1.73 (95\% CI: 1.12-2.67). The HR remained unchanged after adjustment for all potential confounders except birth order and birth weight (partially adjusted models) but increased to 2.31 (1.43-3.73) in the fully adjusted model. Effect estimates were smaller when using exposure 10 years prior to census; however, there was a tendency for higher leukaemia risks with increasing exposure levels in that analysis (Supplemental Material Table S4). We found little evidence of an association with maternal exposure for the group of all cancers, lymphoma, or CNS tumours.

\subsection{Paternal exposure to benzene and childhood cancer}

We found no evidence of association between paternal occupational exposure to benzene and the risk of childhood cancer (Table 3, Supplemental Material Table S4). For all diagnostic groups, IRRs for exposure categories varied around one in both directions and confidence intervals included one.

\subsection{Sensitivity analyses}


Including children of not economically active parents as unexposed increased the sample size fore maternal and paternal exposure by 354,521 and 31,544 children respectively. The results from these analyses were virtually identical to those of our main analyses (Supplemental Material Table S5). When restricting analyses to children born in Switzerland, the observed association between maternal benzene exposure and childhood leukaemia was stronger (HR 1.93, 95\% CI 1.25-2.98) (Supplemental Material Table S6). The association became even stronger when including only children linked to a birth record and when including only children aged 0.4 years at the first census (Supplemental Material Tables S7 and S8 respectively).

\section{Discussion}

\subsection{Main findings}

This nationwide census-based cohort study found an increased risk of leukaemia among children of mothers who were occupationally exposed to benzene at the time of census. The association was strongest among children born in Switzerland and remained unaffected when adjusting for a range of socio-economic factors and residential exposures. We found no evidence of an increased risk for other childhood cancers associated with maternal benzene exposure. Neither did we find evidence of increased risks among children whose fathers were exposed to benzene at work.

\subsection{Embedding in literature}

The findings of our cohort study are in line with recent reviews of studies on the risk of childhood leukaemia and parental exposure to benzene (Carlos-Wallace et al. 2016; Zhou et al. 2014). In their review and meta-analyses, which included mostly case control studies, Carlos-Wallace and colleagues reported stronger associations for maternal (Summary relative risk for highest vs. lowest exposure category: 1.96, 95\% CI:1.39-2.78) compared to paternal exposure (1.23, 1.07-1.41) (Carlos-Wallace et al. 2016). They included studies investigating exposure to benzene at work or from household products, however most included studies were on occupational exposure. When comparing different periods of exposure, effects were stronger for maternal exposure during pregnancy $(2.06,1.51-2.81)$ than for preconceptional exposure $(1.32,0.84-2.08)$. Regarding postnatal exposure, the authors only report a summary estimate for any parental exposure $(1.51,0.99-2.30)$, giving priority to maternal 
exposure when both were reported. This is comparable with the HR found in our study for leukaemia $(1.73,1.12-2.67)$. In a similar meta-analysis, Zhou and colleagues found increased risks for ALL in children of mothers exposed to solvents (summary odds ratio: 1.25, 95\% CI: 1.09-1.45), petroleum products $(1.42,1.10-1.84)$, and paints $(1.23,1.02-1.47)$ (Zhou et al. 2014).

Three recent case-control studies not included in the mentioned reviews reported mixed findings (Bailey et al. 2014; Keegan et al. 2012; Metayer et al. 2016). A large case-control study from the UK looking at a wide range of paternal occupational exposures (33 exposure groups) found a negative association between childhood leukaemia and exposure to exhaust fumes (Keegan et al. 2012). A pooled analysis of 13 case-control studies participating in the Childhood Leukaemia International Consortium (CLIC) found no evidence of an increased risk of childhood leukaemia associated with occupational exposure to paint, neither for paternal nor maternal exposure (Bailey et al. 2014). A recent study from California found an increased risk of childhood leukaemia associated with paternal exposure to organic solvents and benzene, but only for Latino fathers (Metayer et al. 2016). No evidence of association was found for maternal exposure.

Regarding childhood cancers other than leukaemia, increased risks have been reported for CNS tumours in relation to maternal occupational exposure to solvents (Cordier et al. 1997), petroleum products (McKean-Cowdin et al. 1998), diesel exhaust (Peters et al. 2013), and working in the printing (Cordier et al. 2001) or textile industry (Ali et al. 2004), and to paternal occupational exposure to solvents (Keegan et al. 2013; Peters et al. 2014), paints (Colt and Blair 1998; Feychting et al. 2001), and motor vehicle exhaust (Cordier et al. 1997; Cordier et al. 2001; Peters et al. 2013). Similarly, positive associations have been reported for childhood lymphoma and paternal occupation in the shoe and leather industry (Mutanen and Hemminki 2001), non-Hodgkin lymphoma and maternal occupational exposure to solvents (McKinney et al. 2008), and non-Hodgkin lymphoma and paternal exposure to oxygenated solvents and petrol exhaust (Miligi et al. 2013). Our study does not support a causative role of benzene for these cancer types.

\subsection{Strengths and limitations}


A distinguishing feature of our study is that it is a nation-wide cohort study based entirely on routine data. We obtained information on occupations from national censuses, participation in which was compulsory. We assessed outcomes using a population-based cancer registry of high coverage. We thus minimized the risk of selection bias and of differential misclassification of exposure. We cannot however exclude selection bias since the included children, i.e. those with available information on parental occupational exposure, tended to be of higher socioeconomic status. This would only have biased our results if inclusion in the analysis were simultaneously associated with the outcome.

Indeed, the proportion of children linked to a cancer diagnosis was slightly higher among included children than among excluded children (data not shown), probably because the record linkage was more successful for children living in the same household with their parents - a condition for assessing parental occupational exposure and thus an inclusion criterion of the study. Overall, this would have led to an under-representation of exposed cases and thus to an under-estimation rather than to an overestimation of any true effects. Our study was also able to adjust for numerous potential confounders including other environmental exposures and socio-economic position. However, because our study relied entirely on routine data, we could not adjust behavioural factors. We thus cannot exclude residual confounding for instance by parental smoking. Furthermore, our study specifically focused on exposure to benzene using a JEM developed for the Western world. Thus, in contrast to most previous studies which investigated numerous occupational exposures and suffered from multiple testing issues, our study was a confirmatory study regarding occupational exposure to benzene. Also the JEM took into account reductions of workplace exposure during the past decades.

Our study assessed exposure postnatally at a fixed calendar time point (census date) rather than at a given age. This resulted in a wide variation in the age of exposure assessment. In contrast to many other studies, we had no information on prenatal exposures and could not compare different exposure periods. We assessed cancer incidence through record linkage between the SNC and the SCCR. Linkage errors and incomplete linkage (some SCCR cases could not be linked) are likely to have resulted in some misclassification of outcomes. Individual exposures may also have been misclassified as they were assessed based on estimates of mean exposure levels and proportion of exposed workers in a given job category. Previous bias analyses have shown that such aggregation of exposure level 
and probability can bias estimates of exposure outcome relationships and that the direction and magnitude of bias are difficult to predict (Burstyn et al. 2012). Furthermore, we cannot rule out uncontrolled confounding by other workplace exposures that are associated with benzene exposure (Greenland et al. 2016).

\subsection{Interpretation}

A causal interpretation of the observed association between maternal occupational exposure to benzene and childhood leukaemia is plausible. Benzene can cause haematological cancers and we observed the association only for leukaemia. We found no evidence that the association might be due to confounding and, though we cannot exclude misclassification bias, the risk of selection bias was greatly reduced compared to most earlier studies. Furthermore, we found an apparent dose response when using the higher exposure levels prevailing 10 years earlier. Lastly, our findings are in line with the overall evidence from previous studies.

For several reasons, the observed association may be due to exposure during pregnancy rather than to postnatal exposure. First, benzene can cross the placenta and this exposure route could explain why the observed association was limited to maternal exposure. With the exception of breastfeeding (breast milk can contain solvents), other routes by which workplace exposure is transmitted to children would apply to both paternal and maternal exposure. However, although paternal exposure was more common and on average higher, it was not associated with an increased childhood leukaemia risk. Second, effects of maternal exposure were strongest in a subgroup of children who could be linked to a birth record or where younger than 5 years at assessment of maternal occupation (Supplemental Material Tables S7 and S8). The former analysis also showed that the increase in HR observed in the main analyses after adjusting for birth order and birth weight (Table 2), was due to restricting the sample to those linked to a birth record rather than to confounding by birth weight or birth order (the sample must be restricted accordingly when these variables are included). For children linked to a birth record or who were young at the time of census, mothers' jobs held at census may have been same as those during pregnancy. Third, this interpretation is consistent with previous research, which tended to show stronger effects for maternal than paternal exposure and strongest effects for maternal exposure during pregnancy (Carlos-Wallace et al. 2016). 
Assuming that the observed association was causal, the population attributable risk was small and is likely to be smaller today due to even lower exposure levels. In our cohort, about $3 \%$ of the childhood leukaemia cases would have been caused by maternal occupational exposure to benzene, assuming a relative risk of 1.7 and an exposure prevalence of $4.5 \%$ (not economically active mothers included).

\section{Conclusions}

Our study adds new evidence suggesting that maternal occupational exposure to benzene is associated with an increased risk of childhood leukaemia. The distinguishing features of our study include a nationwide cohort design, the sole reliance on routine data, and the specific focus on exposure to benzene. This makes it unlikely that the same observation made in previous case control studies was due to biases which are common in these studies (e.g. selection or recall bias) or to chance findings as a consequence of testing numerous occupational exposures. A plausible explanation for our findings is that maternal exposure to benzene during pregnancy can initiate leukaemia in the developing child. 


\section{Funding:}

This study was supported by the Swiss Federal Office of Public Health (\# 08.001616, \#10.002946, \# 12.008357), Swiss Cancer Research (\# 3049-08-2012, \# 3515-08-2014), and the Swiss Cancer League (\#02224-03-2008). B.D. Spycher was supported by a Swiss National Science Foundation fellowship (PZ00P3_147987).

\section{Acknowledgements:}

The work of the Swiss Childhood Cancer Registry is supported by the Swiss Paediatric Oncology Group (www.spog.ch), Schweizerische Konferenz der kantonalen Gesundheitsdirektorinnen und direktoren (www.gdk-cds.ch), Swiss Cancer Research (www.krebsforschung.ch), Kinderkrebshilfe Schweiz (www.kinderkrebshilfe.ch), the Federal Office of Public Health (FOPH) and the National Institute of Cancer Epidemiology and Registration (www.nicer.org).

The members of the Swiss Pediatric Oncology Group Scientific Committee:

R. A. Ammann (Bern), R. Angst (Aarau), M. Ansari (Geneva), M. Beck Popovic (Lausanne), E. Bergstraesser (Zurich), P. Brazzola (Bellinzona), J. Greiner (St. Gallen), M. Grotzer (Zurich), H. Hengartner (St. Gallen), T. Kuehne (Basel), K. Leibundgut (Bern), F. Niggli (Zurich), J. Rischewski (Lucerne), N. von der Weid (Basel)

The members of the Swiss National Cohort Study Group:

M. Egger (Chairman of the Executive Board), A. Spoerri (University of Bern), M. Zwahlen (University of Bern), M. Puhan (Chairman of the Scientific Board), M. Bopp (University of Zurich), D. Fäh (University of Zurich), N. Künzli (University of Basel), F. Paccaud (University of Lausanne), M. Oris (University of Geneva), M. Schwyn (Swiss Federal Statistical Office, Neuchâtel).

The job exposure matrix (BEN-JEM) used to assess occupational exposure to benzene was developed by one of the authors (Roel Vermeulen) and is available from that author on request.

Competing financial interests: All authors declare they have no actual or potential competing financial interest 


\section{References}

Ali, R.; Yu, C.L.; Wu, M.T.; Ho, C.K.; Pan, B.J.; Smith, T.; Christiani, D.C. A case-control study of parental occupation, leukemia, and brain tumors in an industrial city in Taiwan. Journal of occupational and environmental medicine / American College of Occupational and Environmental Medicine 2004;46:985-992

Anderson, L.M.; Diwan, B.A.; Fear, N.T.; Roman, E. Critical windows of exposure for children's health: cancer in human epidemiological studies and neoplasms in experimental animal models. Environmental health perspectives 2000;108 Suppl 3:573-594

Badham, H.J.; LeBrun, D.P.; Rutter, A.; Winn, L.M. Transplacental benzene exposure increases tumor incidence in mouse offspring: possible role of fetal benzene metabolism. Carcinogenesis $2010 ; 31: 1142-1148$

Bailey, H.D.; Fritschi, L.; Metayer, C.; Infante-Rivard, C.; Magnani, C.; Petridou, E.; Roman, E.; Spector, L.G.; Kaatsch, P.; Clavel, J.; Milne, E.; Dockerty, J.D.; Glass, D.C.; Lightfoot, T.; Miligi, L.; Rudant, J.; Baka, M.; Rondelli, R.; Amigou, A.; Simpson, J.; Kang, A.Y.; Moschovi, M.; Schuz, J. Parental occupational paint exposure and risk of childhood leukemia in the offspring: findings from the Childhood Leukemia International Consortium. Cancer causes \& control : CCC 2014;25:13511367

Bopp, M.; Spoerri, A.; Zwahlen, M.; Gutzwiller, F.; Paccaud, F.; Braun-Fahrlander, C.; Rougemont, A.; Egger, M. Cohort Profile: the Swiss National Cohort--a longitudinal study of 6.8 million people. International journal of epidemiology 2009;38:379-384

Bundesamt für Statistik. Eidgenössische Volkszählung 2000. Abschlussbericht zur Volkszählung 2000. Neuchâtel, Switzerland: Bundesamt für Statistik; 2005.

https://www.bfs.admin.ch/bfsstatic/dam/assets/342380/master (accessed 18.07.2017).

Burstyn, I.; Lavoue, J.; Van Tongeren, M. Aggregation of exposure level and probability into a single metric in job-exposure matrices creates bias. The Annals of occupational hygiene 2012;56:1038-1050 
Carlos-Wallace, F.M.; Zhang, L.; Smith, M.T.; Rader, G.; Steinmaus, C. Parental, In Utero, and EarlyLife Exposure to Benzene and the Risk of Childhood Leukemia: A Meta-Analysis. American journal of epidemiology 2016;183:1-14

Chiu, B.C.; Hou, N. Epidemiology and etiology of non-hodgkin lymphoma. Cancer Treat Res $2015 ; 165: 1-25$

Colt, J.S.; Blair, A. Parental occupational exposures and risk of childhood cancer. Environmental health perspectives 1998;106 Suppl 3:909-925

Cordier, S.; Lefeuvre, B.; Filippini, G.; Peris-Bonet, R.; Farinotti, M.; Lovicu, G.; Mandereau, L. Parental occupation, occupational exposure to solvents and polycyclic aromatic hydrocarbons and risk of childhood brain tumors (Italy, France, Spain). Cancer causes \& control : CCC 1997;8:688-697 Cordier, S.; Mandereau, L.; Preston-Martin, S.; Little, J.; Lubin, F.; Mueller, B.; Holly, E.; Filippini, G.; Peris-Bonet, R.; McCredie, M.; Choi, N.W.; Arsla, A. Parental occupations and childhood brain tumors: results of an international case-control study. Cancer causes \& control : CCC 2001;12:865874

Dowty, B.J.; Laseter, J.L.; Storer, J. The transplacental migration and accumulation in blood of volatile organic constituents. Pediatr Res 1976;10:696-701

Duarte-Davidson, R.; Courage, C.; Rushton, L.; Levy, L. Benzene in the environment: an assessment of the potential risks to the health of the population. Occupational and environmental medicine $2001 ; 58: 2-13$

Fabietti, F.; Ambruzzi, A.; Delise, M.; Sprechini, M.R. Monitoring of the benzene and toluene contents in human milk. Environment international 2004;30:397-401

Feychting, M.; Plato, N.; Nise, G.; Ahlbom, A. Paternal occupational exposures and childhood cancer. Environmental health perspectives 2001;109:193-196

Greenland, S.; Fischer, H.J.; Kheifets, L. Methods to Explore Uncertainty and Bias Introduced by Job Exposure Matrices. Risk Anal 2016;36:74-82 
Hauri, D.D.; Spycher, B.; Huss, A.; Zimmermann, F.; Grotzer, M.; von der Weid, N.; Spoerri, A.; Kuehni, C.E.; Roosli, M.; Swiss National, C.; Swiss Paediatric Oncology, G. Exposure to radiofrequency electromagnetic fields from broadcast transmitters and risk of childhood cancer: a censusbased cohort study. American journal of epidemiology 2014;179:843-851

Heid, I.M.; Kuchenhoff, H.; Miles, J.; Kreienbrock, L.; Wichmann, H.E. Two dimensions of measurement error: classical and Berkson error in residential radon exposure assessment. Journal of exposure analysis and environmental epidemiology 2004;14:365-377

IARC. A review of human carcinogens. Part F: Chemical agents and related occupations. (IARC monographs on the evaluation of carcinogenic risks to humans ). Vol 100F. Lyon, France: International Agency for Research on Cancer (IARC); 2012. http://monographs.iarc.fr/ENG/Monographs/PDFs/index.php (accessed 07 Aug 2015).

Infante-Rivard, C.; Siemiatycki, J.; Lakhani, R.; Nadon, L. Maternal exposure to occupational solvents and childhood leukemia. Environmental health perspectives 2005;113:787-792

Kauppinen, T.; Uuksulainen, S.; Saalo, A.; Makinen, I. Trends of occupational exposure to chemical agents in Finland in 1950-2020. The Annals of occupational hygiene 2013;57:593-609

Keegan, T.J.; Bunch, K.J.; Vincent, T.J.; King, J.C.; O'Neill, K.A.; Kendall, G.M.; Maccarthy, A.; Fear, N.T.; Mfg, M. Case-control study of paternal occupation and childhood leukaemia in Great Britain, 1962-2006. British journal of cancer 2012;

Keegan, T.J.; Bunch, K.J.; Vincent, T.J.; King, J.C.; O'Neill, K.A.; Kendall, G.M.; Maccarthy, A.; Fear, N.T.; Murphy, M.F. Case-control study of paternal occupation and social class with risk of childhood central nervous system tumours in Great Britain, 1962-2006. British journal of cancer 2013;108:1907-1914

McKean-Cowdin, R.; Preston-Martin, S.; Pogoda, J.M.; Holly, E.A.; Mueller, B.A.; Davis, R.L. Parental occupation and childhood brain tumors: astroglial and primitive neuroectodermal tumors. Journal of occupational and environmental medicine / American College of Occupational and Environmental Medicine 1998;40:332-340 
McKinney, P.A.; Raji, O.Y.; van Tongeren, M.; Feltbower, R.G. The UK Childhood Cancer Study: maternal occupational exposures and childhood leukaemia and lymphoma. Radiation protection dosimetry 2008;132:232-240

Metayer, C.; Scelo, G.; Kang, A.Y.; Gunier, R.B.; Reinier, K.; Lea, S.; Chang, J.S.; Selvin, S.; Kirsch, J.; Crouse, V.; Does, M.; Quinlan, P.; Hammond, S.K. A task-based assessment of parental occupational exposure to organic solvents and other compounds and the risk of childhood leukemia in California. Environ Res 2016;151:174-183

Mezei, G.; Borugian, M.J.; Spinelli, J.J.; Wilkins, R.; Abanto, Z.; McBride, M.L. Socioeconomic status and childhood solid tumor and lymphoma incidence in Canada. American journal of epidemiology 2006;164:170-175

Michel, G.; von der Weid, N.X.; Zwahlen, M.; Adam, M.; Rebholz, C.E.; Kuehni, C.E.; Swiss Childhood Cancer, R.; Swiss Paediatric Oncology Group Scientific, C. The Swiss Childhood Cancer Registry: rationale, organisation and results for the years 2001-2005. Swiss Med Wkly 2007;137:502509

Michel, G.; von der Weid, N.X.; Zwahlen, M.; Redmond, S.; Strippoli, M.P.; Kuehni, C.E.; Swiss Paediatric Oncology, G. Incidence of childhood cancer in Switzerland: the Swiss Childhood Cancer Registry. Pediatric blood \& cancer 2008;50:46-51

Miligi, L.; Benvenuti, A.; Mattioli, S.; Salvan, A.; Tozzi, G.A.; Ranucci, A.; Legittimo, P.; Rondelli, R.; Bisanti, L.; Zambon, P.; Cannizzaro, S.; Kirchmayer, U.; Cocco, P.; Celentano, E.; Assennato, G.; Merlo, D.F.; Mosciatti, P.; Minelli, L.; Cuttini, M.; Torregrossa, V.; Lagorio, S.; Haupt, R.; Risica, S.; Polichetti, A.; Group, S.W.; Magnani, C. Risk of childhood leukaemia and non-Hodgkin's lymphoma after parental occupational exposure to solvents and other agents: the SETIL Study. Occupational and environmental medicine 2013;70:648-655

Mutanen, P.; Hemminki, K. Childhood cancer and parental occupation in the Swedish Family-Cancer Database. Journal of occupational and environmental medicine / American College of Occupational and Environmental Medicine 2001;43:952-958 
Panczak, R.; Galobardes, B.; Voorpostel, M.; Spoerri, A.; Zwahlen, M.; Egger, M.; Swiss National, C.; Swiss Household, P. A Swiss neighbourhood index of socioeconomic position: development and association with mortality. Journal of epidemiology and community health 2012;66:1129-1136

Peters, S.; Glass, D.C.; Greenop, K.R.; Armstrong, B.K.; Kirby, M.; Milne, E.; Fritschi, L. Childhood brain tumours: associations with parental occupational exposure to solvents. British journal of cancer 2014

Peters, S.; Glass, D.C.; Reid, A.; de Klerk, N.; Armstrong, B.K.; Kellie, S.; Ashton, L.J.; Milne, E.;

Fritschi, L. Parental occupational exposure to engine exhausts and childhood brain tumors.

International journal of cancer Journal international du cancer 2013;132:2975-2979

Pyatt, D.; Hays, S. A review of the potential association between childhood leukemia and benzene.

Chemico-biological interactions 2010;184:151-164

Reid, A.; Glass, D.C.; Bailey, H.D.; Milne, E.; Armstrong, B.K.; Alvaro, F.; Fritschi, L. Parental occupational exposure to exhausts, solvents, glues and paints, and risk of childhood leukemia. Cancer causes \& control : CCC 2011;22:1575-1585

Schindler, M.; Mitter, V.; Bergstraesser, E.; Gumy-Pause, F.; Michel, G.; Kuehni, C.E.; Swiss Paediatric Oncology, G. Death certificate notifications in the Swiss Childhood Cancer Registry: assessing completeness and registration procedures. Swiss Med Wkly 2015;145:w14225

Schuz, J.; Kaletsch, U.; Meinert, R.; Kaatsch, P.; Michaelis, J. Risk of childhood leukemia and parental self-reported occupational exposure to chemicals, dusts, and fumes: results from pooled analyses of German population-based case-control studies. Cancer epidemiology, biomarkers \& prevention : a publication of the American Association for Cancer Research, cosponsored by the American Society of Preventive Oncology 2000;9:835-838

Schuz, J.; Spector, L.G.; Ross, J.A. Bias in studies of parental self-reported occupational exposure and childhood cancer. American journal of epidemiology 2003;158:710-716 
Shu, X.O.; Stewart, P.; Wen, W.Q.; Han, D.H.; Potter, J.D.; Buckley, J.D.; Heineman, E.; Robison, L.L. Parental occupational exposure to hydrocarbons and risk of acute lymphocytic leukemia in offspring. Cancer Epidem Biomar 1999;8:783-791

Spoerri, A.; Zwahlen, M.; Egger, M.; Bopp, M. The Swiss National Cohort: a unique database for national and international researchers. International journal of public health 2010;55:239-242

Spycher, B.D.; Feller, M.; Roosli, M.; Ammann, R.A.; Diezi, M.; Egger, M.; Kuehni, C.E. Childhood cancer and residential exposure to highways: a nationwide cohort study. European journal of epidemiology 2015a;30:1263-1275

Spycher, B.D.; Lupatsch, J.E.; Zwahlen, M.; Roosli, M.; Niggli, F.; Grotzer, M.A.; Rischewski, J.; Egger, M.; Kuehni, C.E.; Swiss Pediatric Oncology, G.; Swiss National Cohort Study, G. Background ionizing radiation and the risk of childhood cancer: a census-based nationwide cohort study.

Environmental health perspectives 2015b;123:622-628

Steliarova-Foucher, E.; Stiller, C.; Lacour, B.; Kaatsch, P. International Classification of Childhood Cancer, third edition. Cancer 2005;103:1457-1467

Vlaanderen, J.; Lan, Q.; Kromhout, H.; Rothman, N.; Vermeulen, R. Occupational benzene exposure and the risk of lymphoma subtypes: a meta-analysis of cohort studies incorporating three study quality dimensions. Environmental health perspectives 2011;119:159-167

Vlaanderen, J.; Lan, Q.; Kromhout, H.; Rothman, N.; Vermeulen, R. Occupational benzene exposure and the risk of chronic myeloid leukemia: a meta-analysis of cohort studies incorporating study quality dimensions. American journal of industrial medicine 2012;55:779-785

Wallace, L. Environmental exposure to benzene: an update. Environmental health perspectives 1996;104 Suppl 6:1129-1136

Zhou, Y.; Zhang, S.; Li, Z.; Zhu, J.; Bi, Y.; Bai, Y.; Wang, H. Maternal benzene exposure during pregnancy and risk of childhood acute lymphoblastic leukemia: a meta-analysis of epidemiologic studies. PLoS One 2014;9:e110466 
Table 1: Characteristics of children included in main analyses

$\begin{array}{llll}\text { Characteristics } & \text { Included for } & \text { Included for } & \text { Excluded from }\end{array}$
maternal exposure paternal exposure main analyses ${ }^{a}$

Total

$1,138,826(100.0) \quad 1,664,801(100.0) \quad 305,908(100.0)$

Sex

Female

$557,008(48.9)$

$811,882(48.8)$

$147,588(48.2)$

Age at entry into cohort (time of exposure assessment)

$0-4$ years

5-9 years

10-15 years
$407,021(35.7)$

$410,524(36.0)$

$321,281(28.2)$
$637,619(38.3)$

$614,591(36.9)$

$412,591(24.8)$
$112,039(36.6)$

$130,037(42.5)$

$63,832(20.9)$

Educational level of household reference

person

Compulsory education or less

$189,324(16.6)$

$263,216(15.8)$

$85,727(28.0)$

Upper secondary level education

$599,170(52.6)$

$861,097(51.7)$

$102,309(33.4)$

Tertiary level education

$344,912(30.3)$

$531,705(31.9)$

$50,450(16.5)$

Not known

$5,420(0.5)$

$8,783(0.5)$

$67,422(22.0)$

Number of persons per room (tertiles)

$<0.81$

$442,673(38.9)$

$581,433(34.9)$

$110,624(36.2)$

$0.81-1.00$

432,030 (37.9)

$643,743(38.7)$

$80,422(26.3)$

$>1.00$

$264,123(23.2)$

$439,625(26.4)$

$114,862(37.5)$

Neighbourhood socioeconomic position (quintiles, low to high)

Q1

Q2

Q3

Q4

Q5

Missing

Degree of urbanisation

$\begin{array}{rrr}286,167(25.1) & 432,596(26.0) & 102,392(33.5) \\ 231,376(20.3) & 341,450(20.5) & 62,728(20.5) \\ 219,063(19.2) & 316,828(19.0) & 50,778(16.6) \\ 210,523(18.5) & 300,043(18.0) & 40,546(13.3) \\ 182,130(16.0) & 258,645(15.5) & 30,242(9.9) \\ 9,567(0.8) & 15,239(0.9) & 19,222(6.3)\end{array}$


Urban centers

Peri-urban

Rural

\section{Parental occupational exposure to}

benzene $^{b}$

none

$>0-2$

$>2-10$

$>10$
$274,800(24.1)$

$534,589(46.9)$

329,437 (28.9)
$362,634(21.8)$ $769,986(46.3)$

$532,181(32.0)$
96,798 (31.6)

$128,458(42.0)$

$80,652(26.4)$

$\begin{array}{rrr}1,071,893(94.1) & 1,430,246(85.9) & \text { N.A. } \\ 61,851(5.4) & 193,407(11.6) & \text { N.A. } \\ 4,561(0.4) & 25,799(1.5) & \text { N.A. } \\ 521(0.0) & 15,349(0.9) & \text { N.A. }\end{array}$

N.A. not available

Data represent number of children and column percentages (in parenthesis). Children included in main analyses of maternal and paternal exposure partially overlap: 980,271 children are included in both. P-values from $\chi^{2}$-tests for differences between included and excluded children are $<0.001$ for all characteristics except for sex and paternal exposure $(\mathrm{P}=0.055)$

${ }^{\text {a }}$ Children not included in main analyses (neither maternal nor paternal exposure) because parents were not identified, benzene exposure could not be assessed for identified parents (occupation not reported or uncertain, or not economically active), or because they were diagnosed with cancer before entry into the cohort (Figure 1). In sensitivity analyses, we classified not economically active parents (e.g. house-makers, students and pensioners) as unexposed allowing to additionally include 114,638 $(37.5 \%)$ of these children.

${ }^{\mathrm{b}}$ Product of the proportion of workers exposed and the level of exposure [ppm] (at time of census) based on a job exposure matrix (BEN-JEM) and occupation at census 
Table 2: Association between maternal occupational exposure ${ }^{\text {a }}$ to benzene and childhood cancer

\begin{tabular}{|c|c|c|c|c|c|c|}
\hline Outcome & $\begin{array}{l}\text { Exposure } \\
\text { category }\end{array}$ & Cases $^{b}$ & $\begin{array}{c}\text { IR per } \\
100,000 \text { PY }\end{array}$ & $\begin{array}{c}\text { Minimally } \\
\text { adjusted model }\end{array}$ & $\begin{array}{c}\text { Partially } \\
\text { adjusted model }^{\mathrm{d}}\end{array}$ & $\begin{array}{c}\text { Fully adjustec } \\
\text { model }^{\mathrm{e}}\end{array}$ \\
\hline & & & & HR $(95 \%$ CI $)$ & HR $(95 \%$ CI $)$ & HR $(95 \%$ CI $)$ \\
\hline
\end{tabular}

\begin{tabular}{lrrrccc}
\hline Any Cancer & none & 946 & 11.13 & 1.00 & 1.00 & 1.00 \\
& $>0$ & 58 & 11.89 & $1.15(0.88,1.51)$ & $1.17(0.89,1.54)$ & $1.20(0.87,1.66)$ \\
Leukaemia & none & 262 & 3.08 & 1.00 & 1.00 & 1.00 \\
ALL & $>0$ & 23 & 4.72 & $1.73(1.12,2.67)$ & $1.73(1.11,2.69)$ & $2.31(1.43,3.73)$ \\
& none & 205 & 2.41 & 1.00 & 1.00 & 1.00 \\
AML & $>0$ & 19 & 3.90 & $1.88(1.16,3.04)$ & $1.92(1.18,3.13)$ & $2.63(1.58,4.38)$ \\
& none & 44 & 0.52 & 1.00 & 1.00 & 1.00 \\
Lymphoma & $>0$ & 3 & 0.62 & $1.19(0.36-3.87)$ & $1.05(0.32-3.48)$ & $0.65(0.09-4.88)$ \\
& none & 178 & 2.09 & 1.00 & 1.00 & 1.00 \\
NHL & $>0$ & 8 & 1.64 & $0.75(0.37,1.53)$ & $0.79(0.39,1.62)$ & $0.42(0.13,1.34)$ \\
& none & 102 & 1.20 & 1.00 & 1.00 & 1.00 \\
CNS tumours & $>0$ & 3 & 0.62 & $0.51(0.16-1.62)$ & $0.55(0.17-1.76)$ & $0.27(0.04-1.96)$ \\
& none & 220 & 2.59 & 1.00 & 1.00 & 1.00 \\
& $>0$ & 7 & 1.44 & $0.67(0.31,1.43)$ & $0.67(0.31,1.43)$ & $0.40(0.13,1.26)$ \\
& none & 133 & 1.57 & 1.00 & 1.00 & 1.00 \\
& $>0$ & 3 & 0.62 & $0.52(0.16,1.65)$ & $0.53(0.16,1.68)$ & $0.22(0.03,1.60)$
\end{tabular}

Abbreviations: ALL acute lymphoblastic leukaemia, AML acute myeloid leukaemia, CNS central nervous system, HR hazard ratio, IR Incidence ratio, PY person years, NHL non-Hodgkin lymphoma

${ }^{\text {a }}$ Product of the proportion of workers exposed and the level of exposure [ppm] (10 years prior to census) based on a job exposure matrix (BEN-JEM) and occupation at census.

${ }^{\mathrm{b}}$ Number of cases in the minimally adjusted model. The total number of cases (any cancer) was 1004, 1000, and 773 in the minimally partial, partially and fully adjusted models respectively.

${ }^{c}$ Adjusted for sex, year of birth, and census (1990, 2000) 
${ }^{\mathrm{d}}$ Additionally (to ${ }^{\mathrm{c}}$ ) adjusted for education, crowding, neighbourhood socioeconomic position, background ionizing radiation, and electromagnetic fields from radio and TV transmitters, and distance to nearest highway, petroleum refinery, petrol station, and motor vehicle service station.

${ }^{\mathrm{e}}$ Additionally (to ${ }^{\mathrm{d}}$ ) adjusted for birth order and birth weight (only includes children born in Switzerland and linked to a birth record) 
Table 3: Association between paternal occupational exposure ${ }^{a}$ to benzene and childhood cancer

\begin{tabular}{|c|c|c|c|c|c|c|}
\hline \multirow[t]{2}{*}{ Outcome } & $\begin{array}{l}\text { Exposure } \\
\text { category }\end{array}$ & Cases $^{b}$ & $\begin{array}{c}\text { IR per } \\
100,000 \mathrm{PY}\end{array}$ & $\begin{array}{c}\text { Minimally } \\
\text { adjusted model }^{\mathrm{c}}\end{array}$ & $\begin{array}{c}\text { Partially } \\
\text { adjusted model }^{\mathrm{d}}\end{array}$ & $\begin{array}{c}\text { Fully adjusted } \\
\text { model }^{\mathrm{e}}\end{array}$ \\
\hline & & & & HR $(95 \%$ CI $)$ & HR $(95 \%$ CI $)$ & HR $(95 \%$ CI $)$ \\
\hline
\end{tabular}

\begin{tabular}{|c|c|c|c|c|c|c|}
\hline \multirow[t]{3}{*}{ Any Cancer } & none & 1265 & 11.23 & 1.00 & 1.00 & 1.00 \\
\hline & $>0-2$ & 173 & 10.81 & $1.00(0.85,1.18)$ & $1.02(0.86,1.20)$ & $1.03(0.85,1.25)$ \\
\hline & $>2$ & 41 & 12.13 & $1.12(0.82,1.54)$ & $1.14(0.83,1.56)$ & $1.21(0.85,1.73)$ \\
\hline \multirow[t]{3}{*}{ Leukaemia } & none & 380 & 3.37 & 1.00 & 1.00 & 1.00 \\
\hline & $>0-2$ & 49 & 3.06 & $0.97(0.71,1.32)$ & $0.96(0.70,1.32)$ & $0.99(0.69,1.42)$ \\
\hline & $>2$ & 9 & 2.66 & $0.84(0.43,1.63)$ & $0.82(0.42,1.61)$ & $1.00(0.49,2.04)$ \\
\hline \multirow[t]{3}{*}{ ALL } & none & 297 & 2.64 & 1.00 & 1.00 & 1.00 \\
\hline & $>0-2$ & 38 & 2.37 & $0.97(0.68,1.38)$ & $0.98(0.68,1.39)$ & $1.05(0.71,1.55)$ \\
\hline & $>2$ & 6 & 1.78 & $0.72(0.32,1.64)$ & $0.73(0.32,1.64)$ & $0.79(0.32,1.94)$ \\
\hline \multirow[t]{3}{*}{ AML } & none & 55 & 0.49 & 1.00 & 1.00 & 1.00 \\
\hline & $>0-2$ & 10 & 0.62 & $1.25(0.62-2.53)$ & $1.18(0.58-2.39)$ & $1.14(0.45-2.86)$ \\
\hline & $>2$ & 3 & 0.89 & $1.77(0.55-5.77)$ & $1.59(0.49-5.18)$ & $2.66(0.79-9.00)$ \\
\hline \multirow[t]{3}{*}{ Lymphoma } & none & 235 & 2.09 & 1.00 & 1.00 & 1.00 \\
\hline & $>0-2$ & 37 & 2.31 & $1.08(0.76,1.55)$ & $1.11(0.77,1.60)$ & $1.26(0.83,1.91)$ \\
\hline & $>2$ & 9 & 2.66 & $1.25(0.64,2.45)$ & $1.27(0.65,2.50)$ & $1.25(0.55,2.86)$ \\
\hline \multirow[t]{3}{*}{ NHL } & none & 127 & 1.13 & 1.00 & 1.00 & 1.00 \\
\hline & $>0-2$ & 19 & 1.19 & $1.04(0.63-1.71)$ & $1.06(0.64-1.77)$ & $1.03(0.57-1.87)$ \\
\hline & $>2$ & 7 & 2.07 & $1.81(0.83-3.91)$ & $1.85(0.85-4.02)$ & $1.45(0.52-4.01)$ \\
\hline \multirow[t]{3}{*}{ CNS tumours } & none & 300 & 2.66 & 1.00 & 1.00 & 1.00 \\
\hline & $>0-2$ & 32 & 2.00 & $0.89(0.61,1.30)$ & $0.94(0.64,1.39)$ & $0.89(0.57,1.40)$ \\
\hline & $>2$ & 7 & 2.07 & $0.92(0.43,1.96)$ & $0.98(0.46,2.09)$ & $1.34(0.62,2.87)$ \\
\hline \multirow[t]{2}{*}{ Glioma } & none & 170 & 1.51 & 1.00 & 1.00 & 1.00 \\
\hline & $>0-2$ & 21 & 1.31 & $1.09(0.68,1.77)$ & $1.13(0.69,1.83)$ & $1.14(0.66,1.99)$ \\
\hline
\end{tabular}




$$
\begin{array}{llllll}
> & 4 & 1.18 & 0.98(0.36,2.68) & 1.04(0.38,2.83) & 1.41(0.51,3.90)
\end{array}
$$

Abbreviations: ALL acute lymphoblastic leukaemia, AML acute myeloid leukaemia, CNS central nervous system, HR hazard ratio, IR Incidence ratio, PY person years, NHL non-Hodgkin lymphoma

${ }^{\text {a }}$ Product of the proportion of workers exposed and the level of exposure [ppm] (at time of census) based on a job exposure matrix (BEN-JEM) and occupation at census.

${ }^{\mathrm{b}}$ Number of cases in the minimally adjusted model. The total number of cases (any cancer) was 1479, 1469, and 1196 in the minimally partial, partially and fully adjusted models respectively.

${ }^{\mathrm{c}}$ Adjusted for sex, year of birth, and census (1990, 2000)

${ }^{\mathrm{d}}$ Additionally (to ${ }^{\mathrm{c}}$ ) adjusted for education, crowding, neighbourhood socioeconomic position, background ionizing radiation, and electromagnetic fields from radio and TV transmitters, and distance to nearest highway, petroleum refinery, petrol station, and motor vehicle service station.

${ }^{\mathrm{e}}$ Additionally (to ${ }^{\mathrm{d}}$ ) adjusted for birth order and birth weight (only includes children born in Switzerland and linked with birth registry data) 
Figure Legend

Figure 1: Flow-chart of included parent-child pairs 